\title{
Hypoxia and the neonatal rabbit lung: neuroendocrine cell numbers, 5-HT fluorescence intensity, and the relationship to arterial thickness
}

\author{
IM KEITH, JA WILL
}

From the Department of Veterinary Science, University of Wisconsin, Madison, Wisconsin, USA

ABSTRACT We assessed the dynamics of neuroendocrine (NE) cell numbers, the intensity of specific 5-HT fluorescence, and the arterial medial thickness in the lungs of neonatal rabbits in normoxia and acute and chronic hypoxia. Hypoxic neonates had significantly higher NE cell numbers and medial thickness of the pulmonary arteries at 5 days of age than did normoxic controls; 1- and 3-day-old young that died in hypoxia also had significantly higher cell numbers and medial thickness than did hypoxic survivors. A decline in these cell numbers was noted between 1 and 5 days of age among normoxic young, whereas there was no significant change among hypoxic young. Medial thickness was unchanged among normoxic young but increased between 1 and 5 days of age among hypoxic survivors. A 1-day exposure to normoxia of hypoxic young four days postpartum caused a decrease in NE cell numbers and medial thickness to more normal values. Serotonin (5-HT) fluorescence intensity levels of groups of NE cells or neuroepithelial bodies (NEBs) in this group were equal to those of normal controls although these levels were decreased in early chronic hypoxia. Medial thickness and NE cell numbers were inversely correlated with serotonin levels, suggesting that serotonin may be associated with medial hypertrophy and presence of argyrophil material. Medial thickness was positively correlated with NE cell numbers. The above findings led to the following summary: pulmonary NE cells respond to changes in airway oxygen levels; hypoxia or decreased oxygen is associated with decreased cellular 5-HT content and an increase in NE cell numbers by argyrophil stain and medial thickness of pulmonary artery walls. The change to normoxia from hypoxia results in higher cellular 5-HT content and decreased NE argyrophil cell numbers along with reduced pulmonary artery wall medial thickness.

Pulmonary vasoconstriction during hypoxia has been studied since 1946, when Von Euler and Liljestrand demonstrated that increased pulmonary arterial pressure was induced by acute hypoxia in the cat. ${ }^{1}$ Hypoxically induced pulmonary hypertension has since been described concomitant with restrictive respiratory disorders ${ }^{2}$ and in animals and man at high altitude. ${ }^{3-6}$

The mechanism is far from being explained. Involvement of the neuroendocrine cells of the lung has been implied in the hypoxic vasoconstrictor response, ${ }^{7-9}$ whereas $\mathrm{CNS}$ reflexes, local $\mathrm{pH}$, and lactic acid do not seem to be primary mechanisms. ${ }^{10-13}$

Address for reprint requests: Dr I M Keith, Department of Veterinary Science, University of Wisconsin, 1655 Linden Drive, Madison, WI 53706, USA.
Pulmonary NE cells are members of the APUD (amine precursor-uptake-decarboxylation) system described by Pearse. ${ }^{14}$ They occur singly as neuroendocrine cells (NECs) or in groups as neuroepithelial bodies (NEBs) in the airway epithelium throughout the respiratory tract. Precursor uptake and cytoplasmic storage of the amines serotonin and dopamine in argyrophil dense-core vesicles (DCVs) has been demonstrated, 1516 as has immunoreactivity to a bombesin-like peptide. ${ }^{17}$ Changes in argyrophil stainability, dense-core vesicle appearance and serotonin concentration are known to occur with hypoxic stimulus. ${ }^{18-21}$

Our objective was to study the changes of pulmonary NE cells in relation to pulmonary vasoconstriction under short-term chronic hypoxia, with and 
without normoxic recovery. This study describes changes of cell numbers and 5-HT fluorescence in these cells as well as changes in pulmonary arterial medial thickness.

\section{Methods}

One-, 3-, and 5-day-old rabbits, born and raised in hypoxia from New Zealand White does, and young born to normoxic does were studied. The hypoxic does were kept in a hypobaric chamber from the twentieth day of gestation at $520 \mathrm{mmHg}$ for $23.5 \mathrm{~h}$ daily at $24^{\circ} \mathrm{C}$ and $50 \pm 5 \% \mathrm{RH}$.

Two litters of 4-day-old hypoxic neonates were allowed to recover from hypoxia for one day. These, and a number of neonates that died in hypoxia on days 1,3 , and 5 , were also included in the study. Treatments and sample sizes are given in tables 1-4.

All live neonates were killed using $1 \mathrm{cc}$ pentobarbital IP for rapid anaesthesia, and decapitation was performed before respiration was impaired. The hypoxic neonates were killed within 15 minutes after the chamber pressure was normalised. The lungs were instilled with Bouin's fixative through a tracheal cannula at a pressure of $11.4 \mathrm{~cm}$ water in an openchest preparation. All six lobes per animal were embedded in paraffin and $7 \mu$-thick serial sagittal sections were silver-stained by the Grimelius method $^{22}$ to locate NECs and NEBs. Miller's elasticVan Gieson counterstain ${ }^{23}$ was used for morphometry, and haematoxylin and eosin for morphology. An average surface area of $1.95 \mathrm{~cm}^{2}$ per animal was scanned, using $450 \times$ magnification, and the counted neuroendocrine cells were expressed as the number of NECs and NEBs seen per $\mathrm{cm}^{2}$. Actual surface area for each section was determined as follows: the entire section was projected on a sheet of paper with known weight per $\mathrm{cm}^{2}$ (enlargement $100 \times$ ). The contours of the image were outlined and cut, and the weight of this paper image was multiplied by a conversion factor $\left[1 \mathrm{~cm}^{2} /\left(\right.\right.$ weight of $\left.\left.1 \mathrm{~cm}^{2} \times 100\right)\right]$. Tests of significance were based on log-transformed cell numbers so that normal statistics could be applied. A two-way ANOVA and Duncan's multiple range test were used to determine significant differences. ${ }^{24}$

To determine pulmonary artery changes we calculated medial thickness (MT) from outer (OD) and inner (ID) diameter at two perpendicular levels in cross-sectional arteries from the right inferior lobe. Ten arteries per animal were measured, ranging in OD from 50 to $100 \mu$. A combination of papertracing and a computerised morphometry system was used for this procedure. Medial thickness was expressed relative to outer diameter, here called arterial index (MT/OD). Statistical tests are based on mean arterial index for each animal.

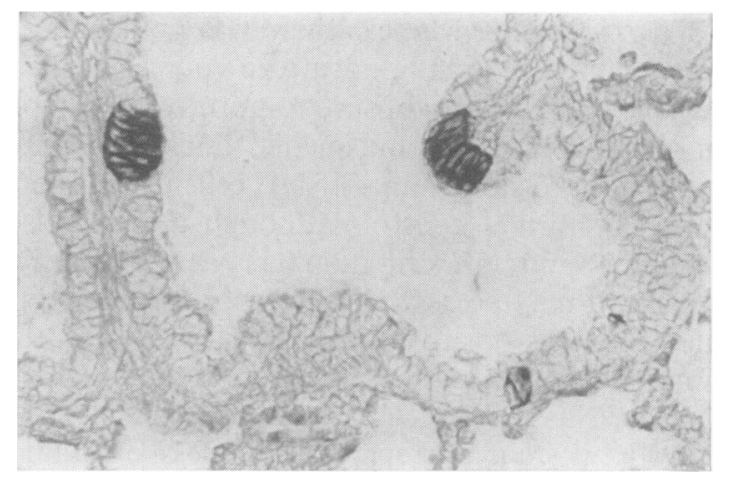

Fig $1 \quad$ NEBs at bronchiolar bifurcations. Grimelius stain, original magnification $\times 375$.

Table 1 Means and standard errors of neuroendocrine cell numbers per $\mathrm{cm}^{2}$ in lung sections of 1-, 3-, and 5-day-old rabbits subjected to different in utero and postpartum oxygen treatments ${ }^{1}$

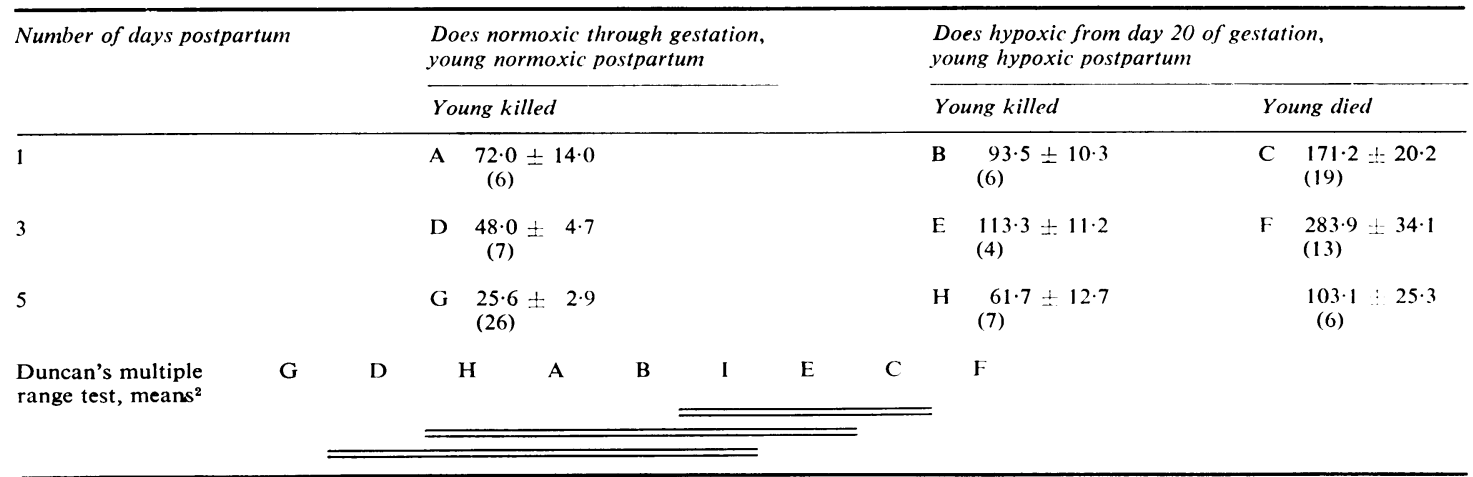

1 Number of young rabbits per treatment is given in parentheses.

2 Analysis of variance disclosed significant differences within days and within treatments; means from groups underscored by the same line were not significantly different at $\mathrm{p} \leqslant 0 \cdot 05$. The means are rearranged in ascending order. 


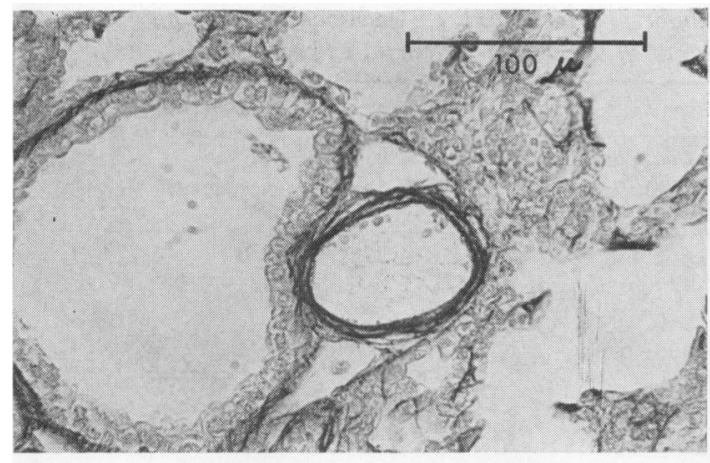

a

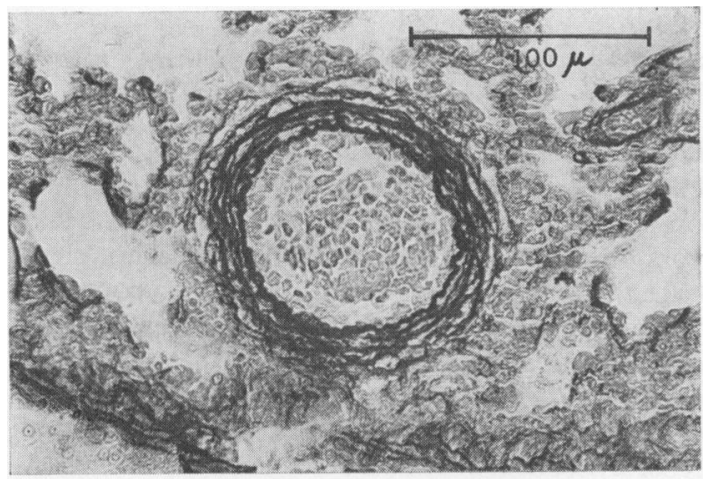

b

Serotonin levels, as determined by fluorescence emission intensities, were measured in NEBs of normoxic and hypoxic neonates. Twenty NEBs were measured from the left inferior lobe in each animal using methods previously described. ${ }^{21} 25$ Treatments and sample sizes are given in tables 3 and 4.

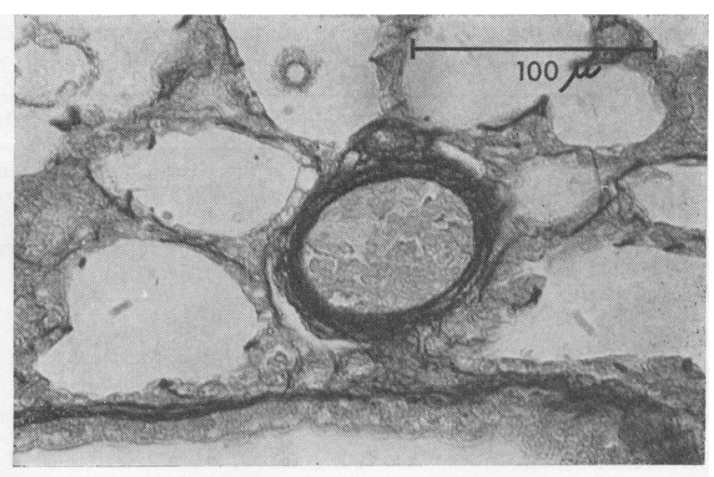

C

Fig 2 (a) Small pulmonary artery from a 5-day-old normoxic rabbit. (b) Small pulmonary artery from a rabbit that died in hypoxia at 5 days of age. Note the separation of elastic laminae indicating persistence of fetal elastic morphology. (c) Small pulmonary artery from a 5-day-old rabbit killed after one day of normoxic recovery from hypoxia. Original magnifications $\times 450$.

\section{Results}

NEUROEN DOCRINE CELL NUMBERS

Single and groups of neuroendocrine cells appeared in the epithelium of all airways studied. The trachea and larynx were not included. NEBs were frequently noted at bifurcations (fig 1).

There was no significant difference in neuroendocrine cell numbers between killed normoxic or hypoxic 1-day-old rabbits (table 1). There were, however, significantly higher cell numbers among killed hypoxic young by days 3 and 5 . Neonates that died in hypoxia on days 1,3 , and 5 had significantly higher cell numbers than normoxic controls, and those that died on days 1 and 3 also had significantly

Table 2 Means and standard errors of arterial indices (medial thickness/outer diameter) in lung sections of 1-, 3-, and 5-day-old rabbits subjected to different in utero and postpartum oxygen treatments ${ }^{1}$

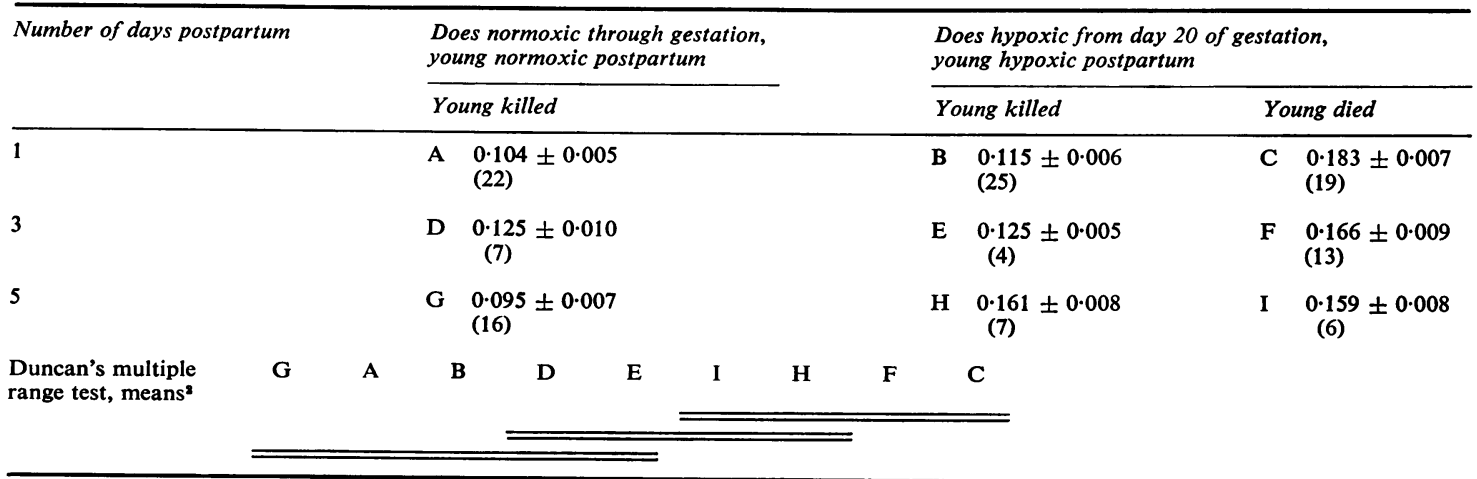

1 Number of young rabbits per treatment is given in parentheses.

${ }^{2}$ Analysis of variance disclosed significant differences within days and within treatments; means from groups underscored by the same line were not significantly different at $p \leqslant 0 \cdot 05$. The means are rearranged in ascending order. 
Table 3 Means and standard errors of neuroendocrine cell numbers, arterial indices, and specific serotonin fluorescence in the lungs of 5-day-old rabbits subjected to different in utero and postpartum oxygen treatments ${ }^{1}$

\begin{tabular}{|c|c|c|c|c|c|c|c|c|c|}
\hline \multirow[b]{3}{*}{$\begin{array}{l}\text { Number of NECs and } \\
\text { NEBs per } \mathrm{cm}^{2}\end{array}$} & \multirow{2}{*}{\multicolumn{2}{|c|}{$\frac{\text { Does normoxic through gestation }}{\text { Young } 5 \text { days in normoxia }}$}} & \multicolumn{4}{|c|}{ Does hypoxic from day 20 of gestation } & \multirow{2}{*}{\multicolumn{3}{|c|}{$\begin{array}{l}\text { Duncan's multiple range } \\
\text { test, means }{ }^{2}\end{array}$}} \\
\hline & & & \multicolumn{2}{|c|}{$\begin{array}{l}\text { Young } 4 \text { days in } \\
\text { hypoxia plus } 1 \text { day } \\
\text { (day 5) in normoxia }\end{array}$} & \multicolumn{2}{|c|}{$\begin{array}{l}\text { Young } 5 \text { days } \\
\text { in hypoxia }\end{array}$} & & & \\
\hline & A & $\begin{array}{l}25 \cdot 6 \pm 2 \cdot 9 \\
(26)\end{array}$ & B & $\begin{array}{l}19 \cdot 6 \pm 4.6 \\
(13)\end{array}$ & $\mathrm{C}$ & $\begin{array}{l}61 \cdot 7 \pm 12 \cdot 7 \\
(7)\end{array}$ & B & A & $\mathrm{C}$ \\
\hline $\begin{array}{l}\text { Arterial index } \\
\text { (medial thickness/ } \\
\text { outer diameter) }\end{array}$ & A & $\begin{array}{l}0.095 \pm 0.007 \\
(16)\end{array}$ & B & $\begin{array}{l}0.119 \pm 0.006 \\
(13)\end{array}$ & $\mathrm{C}$ & $\begin{array}{l}0.161 \pm 0.008 \\
(7)\end{array}$ & A & $\begin{array}{c}\mathrm{B} \\
=\end{array}$ & $\mathrm{C}$ \\
\hline $\begin{array}{l}\text { Serotonin emission } \\
\text { intensity } \\
\text { (relative units) }\end{array}$ & $\mathbf{A}$ & $\begin{array}{l}90 \cdot 8 \pm 6 \cdot 8 \\
(12)\end{array}$ & B & $\begin{array}{l}92 \cdot 0 \pm 3 \cdot 5 \\
(8)\end{array}$ & $\mathrm{C}$ & No data & A & B & \\
\hline
\end{tabular}

1 Number of young rabbits per treatment is given in parentheses.

Analysis of variance disclosed significant differences between treatments; means from groups underscored by the same line were not significantly different at $p \leqslant 0.05$. The means are rearranged in ascending order.

higher cell numbers than their hypoxic survivors.

There was a significant decrease in cell numbers between days 1 and 5 in normoxic young, but no significant change among hypoxic young. Animals that died in hypoxia on day 3 had significantly higher cell numbers than young dying on days 1 and 5 .

PULMONARY VASCULAR CHANGES

Early thickening of the media by medial smooth muscle cells separated the elastic layers and decreased the lumen (fig $2 b$ ). The folding of endothelium and elastica interna was observed in arteries of hypoxic rabbits, and oedema sometimes occurred around vessels where constriction was pronounced.

The differences in arterial index show a pattern similar to that of the neuroendocrine cells (table 2). There were no significant differences in arterial index between killed normoxic or hypoxic neonates on days 1 and 3 , although killed hypoxic young had a

Table 4 Means and standard errors of serotonin emission intensity of NEBs in neonatal rabbit lungs ${ }^{1}$

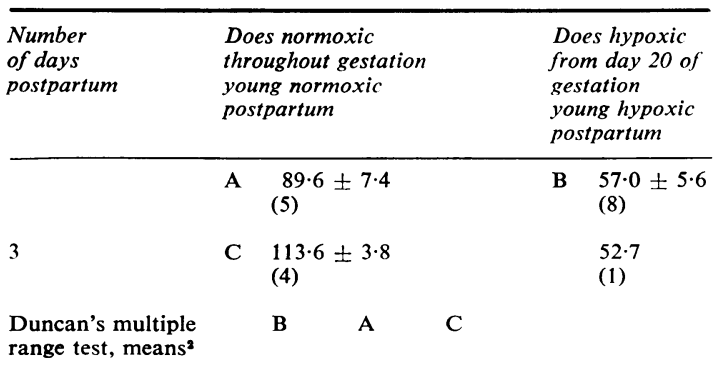

1 Number of young per treatment given in parentheses.

2 Analysis of variance disclosed significant differences within and between treatments; means from groups not underscored by the same line were significantly different from one another at $p \leqslant 0.05$. The means are rearranged in ascending order. Unlabelled means not included. higher index by day 5 . Neonates that died in hypoxia had higher arterial indices than normoxic controls on days 1,3 , and 5 , and higher than hypoxic survivors on days 1 and 3 . Arterial index did not change over the first five days among normoxic controls or those dying in hypoxia, whereas it increased significantly among hypoxic survivors.

\section{SHORT-TERM CHRONIC HYPOXIA WITH}

\section{NORMOXIC RECOVERY}

Neonates that were in hypoxia for four days postpartum and killed after normoxic recovery for one day showed a significant decrease in neuroendocrine cell numbers and arterial indices when compared with hypoxic young killed five days postpartum (table 3). Cell numbers in this recovery group were equal to those of normoxic 5-day-old controls. Arterial indices decreased to a value equal to that in normoxic 5 day-olds, and significantly lower than in $\delta$ any other treatment. The inner elastic lamina had a smooth appearance resembling the normal state (fig 윽 $2 a, c)$.

SEROTONIN FLUORESCENCE OF NEBS

Serotonin levels were significantly lower in hypoxic 1-day-old rabbits than in normoxic controls (table $\mathrm{N}$ 4). We also noted a significant increase in serotonin emission on day 3 in normoxic rabbits. Furthermore, in the hypoxic group with normoxic recovery for one 0 day, serotonin fluorescence was equal to that of $\mathscr{\mathbb { D }}$ normoxic controls (table 3 ).

RELATIONSHIP OF NEUROENDOCRINE CELL NUMBERS AND SEROTONIN LEVELS TO

A R TER IA L INDEX

A regression analysis of individuals in tables 1 and 30 disclosed a significant correlation between neuro- 
endocrine cell numbers and arterial indices $(r=$ $0.62 ; \quad \mathrm{n}=97 ; \quad \mathrm{p}<0.01 ; \quad \mathrm{y}=0.0199 \cdot \ln (\mathrm{x})+$ $0.0567)$. Another regression analysis disclosed a significant negative correlation between serotonin emission values and arterial indices $(\mathrm{r}=-0.48 ; \mathrm{n}=$ $38 ; p<0.01 ; y=-0.0006 x+0.171)$. Furthermore, there was a significant negative correlation between neuroendocrine cell numbers and serotonin emission means $(\mathrm{r}=-0.52 ; \mathrm{n}=38 ; \mathrm{p}<0.01 ; \mathrm{y}=-1.243 \mathrm{x}$ $+168 \cdot 14)$.

\section{OTHER FINDINGS}

Hypoxic neonates frequently had interstitial haemorrhage in ears, nose, tail and feet, and petechiae were observed on lung surfaces and in the gastrointestinal tract. Muscularisation of small arterioles (20-30 $\mu \mathrm{m}$ in diameter) was noticed in hypoxic lungs, especially among young that died. Veins in hypoxic lungs appeared to have thicker walls.

\section{Discussion}

Higher neuroendocrine cell numbers in chronic hypoxic lungs were previously reported by Taylor ${ }^{26}$ in his study of rabbits killed at high altitude. Increased airway oxygen tension appears to be a strong stimulus for reduction in the number of detectable neuroendocrine cells. This was demonstrated in our chronic hypoxic neonates with one day of normoxic recovery (table 3 ). Reduction of argyrophil substance and arterial index appears to occur rapidly and was already noted within 15 minutes after hypoxia. For example, in contrast to above results, HernandezVasquez et $a^{20}$ reported that hypoxic 1- and 5-dayold rabbits had significantly lower cell numbers than normoxic controls. This probably resulted from inadvertently prolonged exposure of hypoxic young to normoxic conditions before killing.

The decline in argyrophil cell numbers after birth, as reported in the normoxic neonates, has been previously demonstrated in rats and rabbits. 1820 This suggests that the neuroendocrine cells may play their most important role during the early neonatal period, and may therefore be involved in adaptation to and maturation of respiration.

No differences in cell numbers and arterial indices were found between 1-day-old rabbits killed in hypoxia or normoxia whereas those dying in hypoxia had higher cell numbers and arterial indices. At day 5 postpartum both hypoxic groups had higher cell numbers and arterial indices than normal controls. This suggests that it is the postnatal oxygen condition that determines the changes seen in hypoxic neonates. These findings are supported by those of Naeye in his studies of pulmonary arteries in normoxaemic infants and infants hypoxaemic secondary to hyaline membrane disease. ${ }^{27}$

A large proportion of the hypoxic young in this study died. They had significantly higher neuroendocrine cell numbers and thicker pulmonary artery walls than their normoxic controls at all ages; they sometimes also differed from their hypoxic survivors. These findings may indicate hypoxic distress. It is known that the response to hypoxia is individual. Adaptation occurs in humans and other mammals but the ability to adapt varies with species, stimulus strength, and genetic disposition. . $^{28-30}$

Previous reports of rats and rabbits exposed to acute hypoxia disclosed a decrease in pulmonary neuroendocrine dense-core granular material, increased exocytosis of dense-core vesicles (DCVs) toward the basement membrane, and decreased formalin-induced fluorescence. ${ }^{181931} \mathrm{We}$ earlier demonstrated that the reduced fluorescence was caused by a loss of serotonin specifically, and that this reduction was not accompanied by a significant change in argyrophil neuroendocrine cell numbers. ${ }^{21}$ This leads to the probability that 5-HT is not responsible for the argyrophilia. This probability is supported by an earlier microspectrographic study which suggested that a polypeptide was present and by our localisation of the tetradecapeptide bombesin. ${ }^{17} 32$ The evidence in the present study supports the view that serotonin is not the argyrophil substance because fluorescence is low in early chronic hypoxia even though the cell numbers by silver stain methods remain constant.

In the present study high neuroendocrine cell numbers and arterial indices rapidly decreased to normal range when hypoxic neonatal rabbits were rendered normoxic. Serotonin levels found to be low in hypoxia, also returned to normal. The normalisation is consistent with the time course of recovery of patients with high-altitude pulmonary hypertension and oedema when treated with supplementary oxygen. ${ }^{33}$ Medial hypertrophy in the pulmonary arteries is reversible but speed and degree of normalisation depends on the duration of the hypoxic stimulus. ${ }^{34}$

The hypothesis of an oxygen-dependent active relaxation of pulmonary arteries was first suggested by Weir ${ }^{35} \mathrm{He}$ postulated that pulmonary vasoconstriction in hypoxia was caused by the absence of oxygendependent relaxation rather than a hypoxia-induced constriction. Oxygen ventilation increases blood levels of the pulmonary vasodilator bradykinin, a nonapeptide. Inhibition of bradykinin metabolising enzyme also elevates bradykinin levels and has been shown to prevent pulmonary artery wall hypertrophy in chronic hypoxia. ${ }^{36}$ Although bradykinin may not be the specific mediator of active normoxic pulmonary vasodilation, there is considerable evidence for this mechanism, and the results of our study 
indicate that the $\mathrm{NE}$ cells of the lung may act as modulating $\mathrm{O}_{2}$ sensors.

The changes in NE cell numbers and cytoplasmic 5-HT fluorescence induced by changes in airway oxygen levels, as recorded in our study, suggest that these cells are oxygen sensors responding to airway hypoxia rather than to hypoxaemia. In a crosscirculation experiment, where alveolar and arterial oxygen levels were altered independently, alveolar hypoxia and not hypoxaemia caused secretory changes in rabbit NEBs. ${ }^{7}$ Hauge similarly noted that hypoxia, not hypoxaemia, elicited the most brisk vasoconstrictor response and concluded that the receptor for hypoxic pulmonary vasoconstriction was closer to the airway than to the vasculature. ${ }^{37}$ Furthermore, Naeye found that prolonged unilateral hypoventilation in dogs, calves, and human infants caused hypertrophy and hyperplasia of small arteries on the ipsilateral side. ${ }^{38}$

It would seem logical and beneficial for the lung to react to local alveolar hypoxia (atelectasis, emphysema, inflammation, and so on) through local or regional arterial constriction, thus shunting blood to better ventilated areas, and making the ventilation-perfusion ratios more uniform. Hypobaric hypoxia or hypoventilation-that is, all airways hypoxic - would then be an extreme situation.

The significant correlations of (1) neuroendocrine cell numbers with arterial indices, and (2) cell numbers and arterial indices with serotonin levels, suggest that the NE cells may be involved in the mechanism of pulmonary vasoconstriction and relaxation. These correlations, under hypoxic and normoxic conditions are not, however, proof of a cause-and-effect relationship. The nature of the interaction between monoamines and polypeptides in the lung is not firmly established and their functions are not fully understood, although evidence of this interaction in many organs exists, and it appears to be only a matter of time before the significance of this relationship to control of the lung is more fully elucidated.

We thank Janice Lokken and Maureen Decorah for histological work and Sharon DeFoliart and Tien Huynh for technical assistance. We are also grateful to Dr Walter Plaut who kindly let us use the fluorescence microscope. The hypobaric chamber at the Biotron, University of Wisconsin-Madison was used for hypoxic treatments. Supported by the College of Agricultural and Life Sciences, University of Wisconsin-Madison and the Council for Tobacco Research Inc USA (grant number 1036).

\section{References}

${ }^{1}$ Von Euler US, Liljestrand G. Observations on the pul- monary arterial blood pressure in the cat. Acta Physiol Scand 1946;12:301-20.

${ }^{2}$ Wagenvoort CA, Wagenvoort $\mathrm{N}$. Hypoxic pulmonary vascular lesions in man at high altitude and in patients with chronic respiratory disease. Pathol Microbiol (Bascl) 1973;39:276-83.

${ }^{3}$ Grover RF. Pulmonary circulation in animals and man at high altitude. Ann NY Acad Sci 1965;127:632-9.

${ }^{4}$ Ruiz AV, Bisgard GE, Tyson IB, Grover RF, Will JA. Regional lung function in calves during acute and chronic pulmonary hypertension. J Appl Physiol 1974; 37:384-91.

${ }^{5}$ Bisgard GE, Orr JA, Will JA. Hypoxic pulmonary hypertension in the pony. Am J Vet Res 1975;36:49-52.

6 Weir EK, Tucker A, Reeves JT, Grover RF. Increased pulmonary vascular pressor response to hypoxia in highland dogs (39615). Proc Soc Exp Biol Med 1977; 154:112-5.

${ }^{7}$ Lauweryns JM, Cokelaere M, Lerut T, Theunynck P. Cross-circulation studies on the influence of hypoxia and hypoxaemia on neuro-epithelial bodies in young rabbits. Cell Tiss Res 1978;193:373-86.

${ }^{8}$ Lloyd TC. Hypoxic pulmonary vasoconstriction: role of perivascular tissue. J Appl Physiol 1968;25:560-5.

${ }^{9}$ Laros CF. Local chemical regulation of the flow resistance $\mathbb{D}$ in the bronchial tree and pulmonary circulation. Respiration $1971 ; 28: 120-36$.

10 Duke $H$. The site of action of anoxia on the pulmonary blood vessels of the cat. J Physiol 1965;125:373-82.

11 Fishman AP. Respiratory gases in the regulation of the pulmonary circulation. Physiol Rev 1960;41:214-60.

12 Lloyd TC. Role of nerve pathway in the hypoxic vasocon- $\bar{\partial}$ striction of lung. J Appl Physiol 1966;21:1351-5.

${ }^{13}$ Tucker A. Pulmonary and systemic vascular responses to $\mathbb{D}$ hypoxia after chemical sympathectomy. Cardiovasc Re's 1979;13:469-76.

14 Pearse AGE. The cytochemistry and ultrastructure of polypeptide hormone-producing cells of the APUD series and the embryologic, physiologic, and pathologic implications of the concept. J Histochem and Cytochem 1969;17:303-13.

${ }^{15}$ Hage E. Amine-handling properties of APUD-cells in the bronchial epithelium of human foetuses and in the epithelium of the main bronchi of human adults. Acta Pathol Microbiol Scand 1973 ;81:64-70.

${ }_{16}$ Lauweryns JM, Cokelaere M, Theunynck P. Serotonin producing neuroepithelial bodies in the rabbit respiratory mucosa. Science 1973;180:410-3.

17 Wharton J, Polak JM, Bloom SR et al. Bombesin-like응 immuno-reactivity in the lung. Nature 1978;273:769-70.

${ }^{18}$ Moosavi H, Smith P, Heath D. The Feyrter cell in hypoxia.0 Thorax 1973;28:729-41.

19 Lauweryns JM, Cokelaere M. Hypoxia-sensitive neuro- $N$ epithelial bodies. Intrapulmonary secretory neuro-receptors modulated by the CNS. Z Zellforsch $1973 ; 145$ : 521-40.

20 Hernandez-Vasquez A, Will JA, Quay WB. Quantitative characteristics of the Feyrter (APUD) cells of the neonatal rabbit lung in normoxia and chronic hypoxiaco Thorax 1977;32:449-56.

${ }_{21}$ Keith IM, Will JA. Pulmonary neuroendocrine cells Decreased serotonin fluorescence and stable argyrophil:cell numbers in acute hypoxia. Cell Tiss Res $1981 ; 214$ 201-5.

22 Grimelius L. A silver nitrate stain for $a_{2}$ cells in huma® pancreatic islets. Acta Societatis Medicorum Upsaliened sis 1968;73:243-70.

${ }^{23}$ Miller PJ. An elastin stain. Med Lab Technol 1971;28 148-9. 
${ }^{24}$ Steel RGD, Torrie JH. Principles and procedures of statistics with special reference to the biological sciences. New York: McGraw-Hill, 1960:112.

${ }^{25}$ Keith IM, Will JA. Standardization of formalin induced fluorescence and its measurement to quantify serotonin emission in pulmonary neuroendocrine cells. 1981 ; submitted for publication.

${ }^{26}$ Taylor W. Pulmonary argyrophil cells at high altitude. $J$ Pathol 1976;122:137-44.

27 Naeye RL, Letts HW. The effects of prolonged neonatal hypoxemia on the pulmonary vascular bed and iseart. Pediatrics 1962;30:902-9.

${ }^{28}$ Grover RF, Vogel JHK, Averill KH, Blount SG. Pulmonary hypertension. Individual and species variability relative to vascular reactivity. Am Heart $J$ 1963;66:1-3.

29 Weir EK, Tucker A, Reeves JT, Will DH, Grover RF. The genetic factor influencing pulmonary hypertension in cattle at high altitude. Cardiovasc Res 1974;8:745-9.

${ }^{30}$ Collins DD, Scoggin CH, Zwillich CW, Weil JV. Hereditary aspects of decreased hypoxic response. J Clin Invest $1978 ; 62: 105-10$.

${ }^{31}$ Lauweryns JM, Cokelaere M, Deelersynder M, Liebens M. Intrapulmonary neuro-epithelial bodies in newborn rabbits. Cell Tiss Res 1977;182:425-40.
${ }^{32}$ Lauweryns JM, Liebens M. Microspectrography of formaldehyde and fluorescamine-induced fluorescence in rabbit pulmonary neuroepithelial bodies: demonstration of a new, probably polypeptide intracytoplasmic substance. Experientia 1977;33:1510-1.

${ }^{33}$ Grover RF, Hultgren HN. Hartley LH. Pathogenesis of acute pulmonary edema at high altitude. In: Guintini $\mathrm{C}$, ed. Central hemodynamics and gas exchange. Turin: Minerva Medica, 1971:409-20.

${ }^{34}$ Dingemans KP, Wagenvoort CA. Pulmonary arteries and veins in experimental hypoxia. Am J Pathol 1978;93: 353-68.

${ }^{35}$ Weir EK. Does normoxic pulmonary vasodilation rather than hypoxic vasoconstriction account for the pulmonary pressor response to hypoxia? Lancet 1978; $1: 476-7$.

${ }^{36}$ Zakheim RM, Mattioli L, Malteni A, Mullis KB, Bartley J. Prevention of pulmonary vascular changes of chronic alveolar hypoxia in the rat. Lab Invest 1975;33:57-61.

37 Hauge A. Hypoxia and pulmonary vascular resistance. The relative effects of pulmonary arterial and alveolar $\mathrm{PO}_{2}$. Acta Physiol Scand 1969;76:121-30.

${ }^{38}$ Naeye RL. Pulmonary vascular changes with chronic unilateral pulmonary hypoxia. Circ Res $1965 ; 17: 160-7$. 